Article

\title{
A Cyclic Plasticity Model with Martensite Transformation for S30408 and Its Finite Element Implementation
}

\author{
Yanan Chen ${ }^{1}$, Xiaohui Chen ${ }^{2}$, Bingjun Gao ${ }^{1, *}$, Xu Chen ${ }^{3}{ }^{\circledR}$, Kai Zhang ${ }^{1}$ and Chulin $\mathrm{Yu}^{1}$ \\ 1 School of Chemical Engineering and Technology, Hebei University of Technology, Tianjin 300130, China; \\ 201721505012@stu.hebut.edu.cn (Y.C.); 201831510001@stu.hebut.edu.cn (K.Z.); yuchulin@hebut.edu.cn (C.Y.) \\ 2 School of Control Engineering, Northeastern University at Qinhuangdao, Qinhuangdao 066004, China; \\ chenxh@neuq.edu.cn \\ 3 School of Chemical Engineering and Technology, Tianjin University, Tianjin 300072, China; xchen@tju.edu.cn \\ * Correspondence: bjgao@hebut.edu.cn
}

Received: 9 July 2020; Accepted: 27 August 2020; Published: 29 August 2020

check for updates

\begin{abstract}
The ability of the constitutive model to simulate the ratcheting behavior of metastable austenitic stainless steel S30408 is significant to ensure the safety of the liquefied natural gas (LNG) semi-trailer tanks in the lightweight process of the inner containers. This is because the lightweight inner vessels often encounter cyclic stresses due to the road inertia loads together with high mean stresses due to internal pressures. In this study, we performed cryogenic uniaxial tension experiments and a series of ratcheting experiments to investigate the cyclic plasticity behavior of the metastable austenitic stainless steel S30408. Based on the Ohno-Wang II model, we proposed a new cyclic plasticity constitutive model with martensitic transformation, which relates the content of deformation-induced martensite with isotropic hardening and kinematic hardening. The ratcheting behaviors of S30408 were first simulated by the proposed model with the incremental loading method using MATLAB. The results showed that the model could reasonably predict the ratcheting behavior of S30408, and the evolution law of martensite content could well predict the content of deformation-induced martensite. Under the assumption of the von Mises yield criterion and normal plasticity flow rule, we developed a numerical algorithm of plastic strain with the proposed model to implement the finite element calculation of the model. Internal iteration in the numerical algorithm was implemented with the Euler backward method, which calculated the trial strain for each equilibrium iteration using the consistent tangent matrix. With a user subroutine, the proposed model was programmed into ANSYS for a user - executable version. By simulating the uniaxial ratcheting of a S30408 round bar, we found that the calculated results were in good agreement with the experimental results, which promises further applications in the design of structures, such as LNG semi-trailer tanks.
\end{abstract}

Keywords: ratcheting behavior; constitutive model; martensitic transformation; finite element

\section{Introduction}

With excellent plasticity and toughness, S30408 austenitic stainless steel (type 304 stainless steel in American Iron and Steel Institute (AISI) materials designation) is often employed in the inner containers of LNG semi-trailer tanks [1]. In practical engineering applications, due to the complex road spectrum load and inertial forces, such as braking and steering, alternating stress is generated in the supporting regions of the inner container. The alternating stress together with the mean stress due to internal pressure becomes sufficiently high to make the material in this area encounter cyclic plasticity and produce gradual plastic strain accumulation, i.e., ratcheting. In the design of practical 
engineering structures, the cumulative damage caused by the ratcheting strain is an important issue to consider for the structural integrity [2].

Many scholars have produced extensive research on the ratcheting behavior of various materials and established a series of constitutive models. The classic Armstrong and Frederick (A-F) [3] model employed nonlinear characteristics due to the introduction of dynamic recovery of backstress and overpredicted ratcheting. Chaboche $[4,5]$ described ratcheting with several A-F models. Ohno and Wang [6,7] introduced a critical state of dynamic recovery; however, multiaxial ratcheting prediction is yet be successfully demonstrated. Many scholars have modified and developed the constitutive model by associating different parameters [8-13].

Cyclic softening and hardening can have a great influence on ratcheting in unsymmetrical stress cycles $[14,15]$. The cyclic softening and hardening behaviors of materials are typically reflected in the isotropic hardening law of the model [16-18]. In order to improve the prediction of ratcheting strain of materials in the constitutive model, Halama [19] modified the model proposed by Abdel-Karim and Ohno, and embedded the cyclic hardening/softening characteristics of materials and additional hardening caused by non-proportional load into the Abdel-Karim model. Chen et al. [20] introduced the evolution rule of function $\phi(p)$ and the parameter $\mu_{i}$ of material cyclic hardening or softening characteristics into the superposition model of the Ohno-Wang II model and A-F model, and improved the prediction effect of strain cyclic and uniaxial ratcheting strain. Wang et al. [21] found that both isotropic hardening and kinematic hardening contributed to the cyclic softening of materials, and modified the Abdel-Karim and Ohno (AKO) model by quantifying the effects of isotropic hardening and kinematic hardening on the cyclic softening of materials.

These studies demonstrated that different materials are of different ratcheting behaviors. S30408 is a metastable austenitic stainless steel. Under the influence of mechanical stress, plastic deformation and a cryogenic temperature service environment, martensitic transformation will be induced [22-24], resulting in significant changes in the mechanical behavior, thus, affecting the fatigue life of the materials. The high strength and toughness of S30408 stainless steel results from the transformation strengthening and plastic growth mechanism. Therefore, the influence of martensitic transformation should be considered in the establishment of a constitutive model.

Sitko et al. [25] studied the plastic behavior of stainless steel at cryogenic temperatures, and put forward a constitutive equation including martensite volume fraction. Yi et al. [26] found that cryogenic temperatures can improve the martensitic transformation rate of austenitic stainless steel AISI 316LN. Naghizadeh et al. [27] modified the expression of the martensite content by discussing different kinetic models of martensite transformation. Cryogenic temperature experiments of metastable austenitic stainless steel found that the martensite content in S30408 showed the rule of rapid growth first and then stability [28]. To correctly describe the effect of the martensite content on the material model, the parameters related to martensite can be associated with kinematic hardening and isotropic hardening in the constitutive model $[29,30]$.

The constitutive models used in commercial software, such as ANSYS and ABAQUS, to predict ratcheting strain are relatively simple; however, these models are not ideal for predicting ratcheting strain. Many scholars [31-34] have written user subroutines by using the secondary development function provided by ANSYS and ABAQUS, and embedded some new constitutive models into the software to predict ratchet deformation, and achieved good prediction results.

In this paper, we tested the ratcheting of this material under different loading conditions. Based on the Ohno-Wang II model, the content of martensite is related to the isotropic hardening and kinematic hardening of materials, and we propose a constitutive model that can reasonably describe the martensitic transformation induced by S30408 at cryogenic temperatures. Then, in the numerical algorithm, we utilized the radial return method to realize the internal equilibrium iteration and determined the tentative strain after each equilibrium iteration by the consistent tangent matrix. Finally, we applied the constitutive model with martensitic transformation to the finite element analysis to 
simulate the ratcheting strain of S30408 round bar. We examined the capability of the proposed constitutive model to predict the uniaxial ratcheting strain of the specimen.

\section{Ratcheting Experiments}

\subsection{Specimen}

The material used in the study was S30408 stainless steel, which was formed as a round bar specimen with a gauge length of $10 \mathrm{~mm}$ and a diameter of $3 \mathrm{~mm}$. The chemical composition of the material is (wt.\%): C 0.02, Si 0.45, Mn 1.16, P 0.026, S 0.001, Cr 18.13, Ni 8.03, and N 0.05. The specimen dimensions used in the experiments are shown in Figure 1.

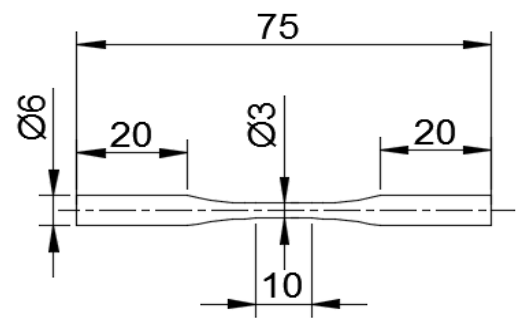

Figure 1. Specimen geometry $(\mathrm{mm})$.

In the experiments, liquid nitrogen was used as the coolant, and the round bar specimen was completely immersed in the cryogenic temperatures box. When the temperature was reduced to $110 \mathrm{~K}$, this was maintained for 15 mins to obtain a uniform temperature of the specimen. During the cryogenic temperature experiments, the temperature deviation was $\pm 2 \mathrm{~K}$.

\subsection{Uniaxial Experiments}

\subsubsection{Uniaxial Tension Experiments}

The uniaxial tension experiments were conducted with the electric servo fatigue multifunctional machine ( $\mathrm{Xi}^{\prime}$ an Li Chuang company, Xi'an, China), and the loading rate was $1.5 \times 10^{-3} / \mathrm{s}$. Figure 2 shows the uniaxial tension curve of the material. Under cryogenic temperatures, a plastic plateau occurs due to the formation of martensite, and secondary hardening can be observed after the plastic plateau due to the deformation-induced martensite and the strong interactions of dislocations of the austenitic with the hardening phase martensite. Although the nominal yield strength $\sigma_{0.2}$ was $330 \mathrm{MPa}$, the initial yield stress $\sigma_{0}$ corresponding to the size of yield surface was only $120 \mathrm{MPa}$, which is used in the later plasticity analysis. It can be seen from Figure 2 that the strain corresponding to the yield platform is $8.3 \%$. In the actual engineering structure, the cyclic load will not exceed $8.3 \%$; thus, the segment of plasticity including the yield platform but without the second hardening section is considered in the subsequent analysis. The mechanical property parameters are shown in Table 1.

Table 1. The mechanical properties.

\begin{tabular}{cccccc}
\hline \multicolumn{5}{c}{ Mechanical Properties } \\
\hline$E / \mathrm{GPa}$ & $\boldsymbol{v}$ & $\sigma_{0} / \mathrm{MPa}$ & $\sigma_{0.2} / \mathrm{MPa}$ & $\sigma_{\mathrm{b}} / \mathbf{M P a}$ & $\delta / \%$ \\
\hline 194 & 0.33 & 120 & 330 & 1324 & 75.4 \\
\hline
\end{tabular}




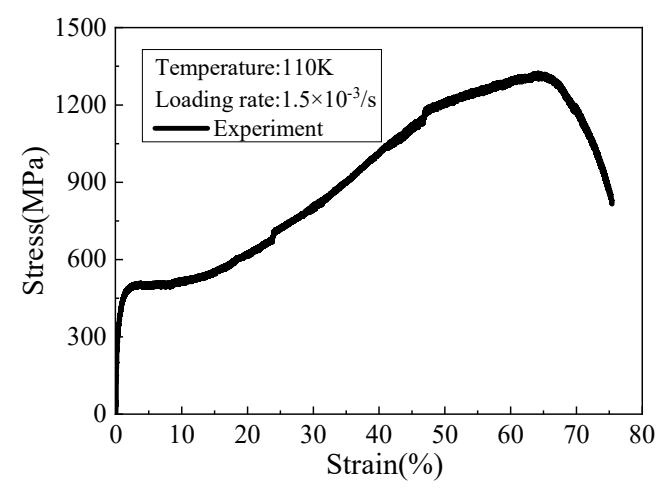

Figure 2. Uniaxial tension curve.

\subsubsection{Uniaxial Ratcheting Experiments}

We performed the uniaxial ratcheting experiments with a EUM - 25K20 tension - torsion fatigue testing machine (CARE Measure \& Control Ltd. Co., Tianjin, China). The triangular fluctuating load was applied to the round bar specimen. The load was controlled with a load rate of $312 \mathrm{MPa} / \mathrm{s}$. The ratcheting strain was measured by an Epsilon cryogenic temperature extensometer (Epsilon Tech. Comp., Jackson, WY 83001, USA). The volume fraction of martensite was determined by a ferrite measuring instrument, FMP30 (HELMUT FISCHER GMBH Co., Hunenberg, Germany). The loading conditions of the ratcheting experiments are shown in Table 2.

Table 2. Ratcheting experiments scheme.

\begin{tabular}{ccccc}
\hline Mean Stress & \multicolumn{4}{c}{ Amplitude Stress $\sigma_{\mathrm{a}} / \mathrm{MPa}$} \\
\cline { 2 - 5 }$\sigma_{\mathrm{m}} / \mathrm{MPa}$ & $\mathbf{1 9 0}$ & $\mathbf{2 1 5}$ & $\mathbf{2 4 0}$ & $\mathbf{2 9 0}$ \\
\hline 240 & & & $\sqrt{ }$ & \\
290 & $\sqrt{ }$ & $\sqrt{ }$ & $\sqrt{ }$ & $\sqrt{ }$ \\
\hline
\end{tabular}

Figure 3 shows the stress-strain response of materials under different loading conditions. The strains accumulated in the direction of the mean stress and the accumulating rates decreased continuously with the increasing cyclic number. In order to quantitatively study the law of plastic strain accumulation under cyclic loading, in this paper, ratcheting strain is defined as:

$$
\varepsilon_{\mathrm{r}}=\frac{\varepsilon_{\max }+\varepsilon_{\min }}{2}
$$

where $\varepsilon_{\max }$ and $\varepsilon_{\min }$ are the maximum and minimum plastic engineering strain in a cycle.

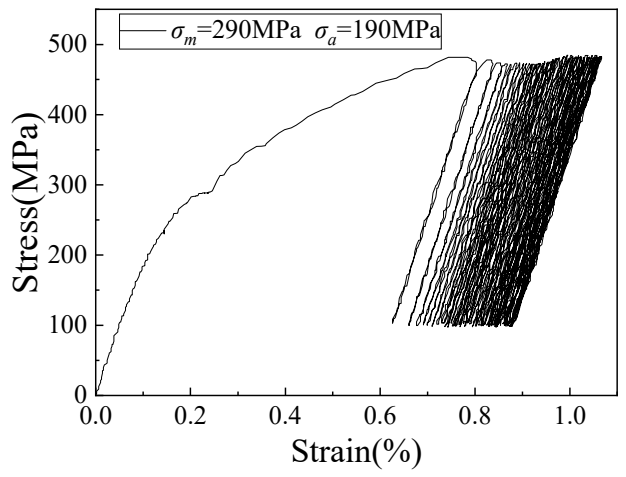

(a)

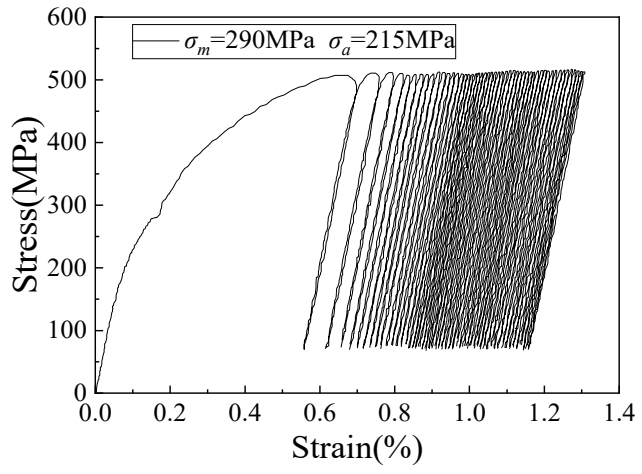

(b)

Figure 3. Cont. 


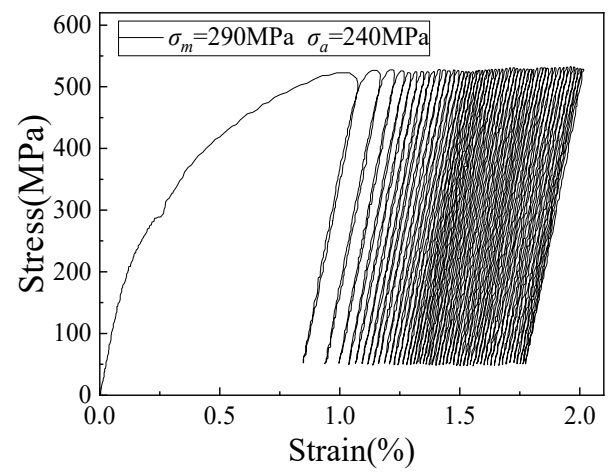

(c)

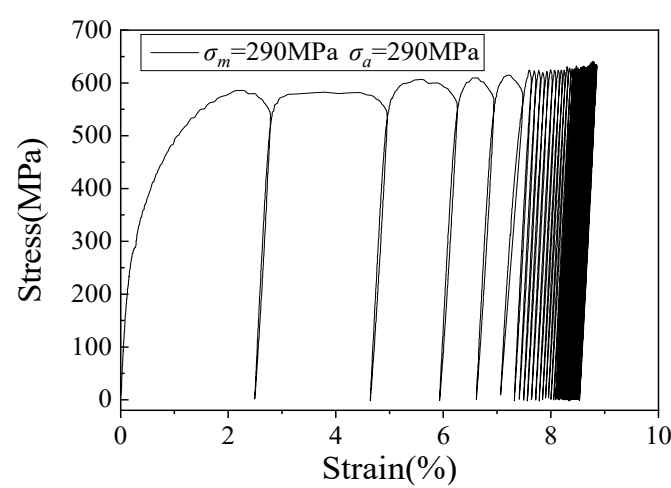

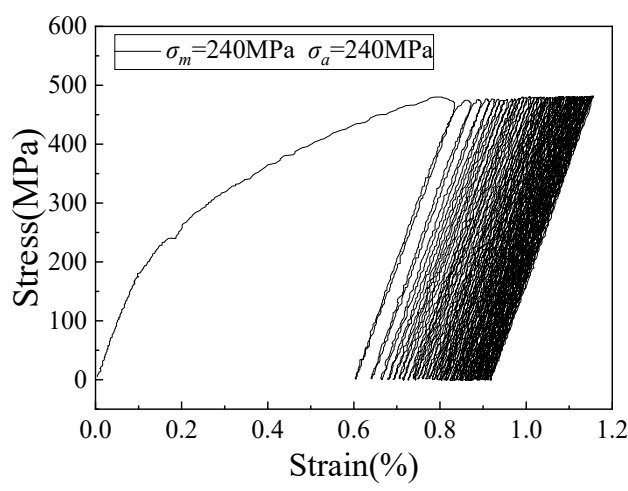

(d)

(e)

Figure 3. The stress-strain response in the first 50 cycles under different loading conditions: (a) $\sigma_{m}=290 \mathrm{MPa} \sigma_{a}=190 \mathrm{MPa}(\mathbf{b}) \sigma_{m}=290 \mathrm{MPa} \sigma_{a}=215 \mathrm{MPa}$ (c) $\sigma_{m}=290 \mathrm{MPa} \sigma_{a}=240 \mathrm{MPa}$ (d) $\sigma_{m}=240 \mathrm{MPa} \sigma_{a}=240 \mathrm{MPa}(\mathbf{e}) \sigma_{m}=290 \mathrm{MPa} \sigma_{a}=290 \mathrm{MPa}$.

The ratcheting strains for various loading conditions are shown in Figure 4. The ratcheting strain of materials accumulated rapidly in the first few cycles, and with the increase of cycles, the ratcheting deformation rate gradually showed a slow trend. As can be seen from Figure 4, when the mean stress remained unchanged, the ratcheting strain increased with the increase of amplitude stress.

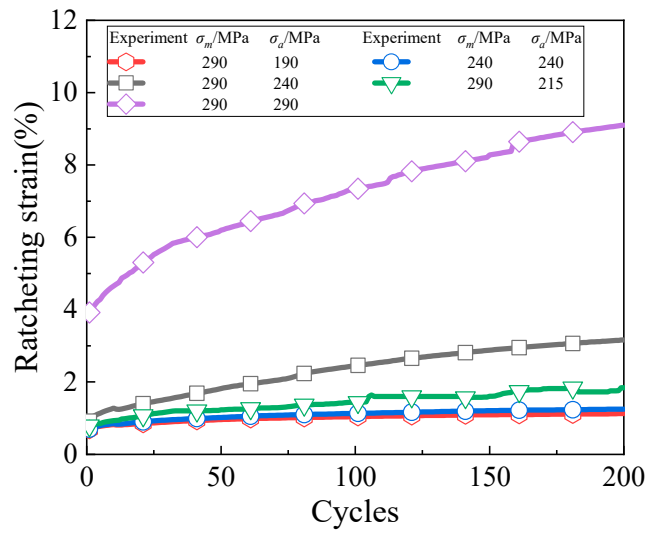

Figure 4. Experimental values of ratcheting.

\section{Constitutive Model and Simulation Results with MATLAB}

\subsection{Several Nonlinear Constitutive Models}

Five advanced constitutive models were tentatively used to simulate the ratcheting strain of cryogenic temperatures for S30408 austenitic stainless steel. 


\section{Ohno-Wang model}

To better describe ratcheting behavior, Ohno and Wang [6] proposed an equation representing the critical state of the dynamic recovery term, and assumed that each component of backstress $\boldsymbol{\alpha}_{i}$ only works when its value reaches the critical value (OW-I). The OW-I model is proposed as follows

$$
\boldsymbol{\alpha}=\sum_{\mathrm{i}=1}^{M} \boldsymbol{\alpha}_{i}, d \boldsymbol{\alpha}_{i}=\frac{2}{3} r_{i} \gamma_{i} d \varepsilon^{p}-\gamma_{i} H\left(f_{i}\right)\left\langle d \varepsilon^{p}: \frac{\boldsymbol{\alpha}_{i}}{\overline{\boldsymbol{\alpha}_{i}}}\right\rangle \boldsymbol{\alpha}_{i}
$$

where $f_{i}=\bar{\alpha}_{\mathrm{i}}^{2}-r_{i}^{2}$. However, the OW-I model produces closed hysteresis loops and hence cannot simulate uniaxial ratcheting. To eliminate this limitation, Ohno and Wang [7] proposed a slight nonlinearity for each rule by introducing an exponential relation, and before reaching its critical state, the dynamic recovery term is partially operative (OW-II). The formula is proposed as follows

$$
\boldsymbol{\alpha}=\sum_{\mathrm{i}=1}^{M} \boldsymbol{\alpha}_{i}, d \boldsymbol{\alpha}_{i}=\frac{2}{3} r_{i} \gamma_{i} d \varepsilon^{p}-\gamma_{i}\left(\frac{\overline{\boldsymbol{\alpha}_{i}}}{\mathrm{r}_{i}}\right)^{m_{i}}\left\langle d \varepsilon^{p}: \frac{\boldsymbol{\alpha}_{i}}{\overline{\boldsymbol{\alpha}_{i}}}\right\rangle \boldsymbol{\alpha}_{i}
$$

\section{AKO model and its modification}

To improve the description of the uniaxial ratcheting behavior of the OW-I model, Abdel-Karim [8] combined the OW-I model with the A-F model (AKO). The AKO model is proposed in the following form

$$
\boldsymbol{\alpha}=\sum_{\mathrm{i}=1}^{M} \boldsymbol{\alpha}_{i}, d \boldsymbol{\alpha}_{i}=\frac{2}{3} r_{i} \gamma_{i} d \varepsilon^{p}-\mu_{\mathrm{i}} \gamma_{i} \boldsymbol{\alpha}_{i} d p-\gamma_{i} H\left(f_{i}\right)\left\langle d \lambda_{i}\right\rangle \boldsymbol{\alpha}_{i}
$$

where $\mathrm{d} \lambda_{i}=d \varepsilon^{p}: \frac{\boldsymbol{\alpha}_{i}}{r_{i}}-\mu_{i} d p$.

Hamala [19] revised the $\mu_{i}$ in the AKO model (AKO IV), where the $\mu_{i}$ is expressed as follows

$$
\begin{gathered}
\mu_{\mathrm{i}}=\eta\left(\frac{\partial f}{\partial \sigma}: \frac{\boldsymbol{\alpha}_{i}}{\bar{\alpha}_{i}}\right\rangle^{\chi}, d \eta=d \eta_{1}+d \eta_{2} . \\
\mathrm{d} \eta_{1}=\omega_{1}\left(\eta_{\infty 1}-\eta_{1}\right) d p, \mathrm{~d} \eta_{2}=\omega_{2}\left(\eta_{\infty 2}-\eta_{2}\right) d p .
\end{gathered}
$$

where $\mu_{i}$ is the ratcheting parameter, $\eta$ is a parameter affecting the ratchet deformation, $\eta_{\infty 1}, \eta_{\infty 2}, \eta_{1}$, $\eta_{2}, \omega_{1}$ and $\omega_{2}$ are material constants, $\mathrm{d} p$ is the magnitude of the plastic strain increment tensor, and $\chi$ is the multiaxial parameter. The uniaxial ratcheting studied in this study is $\chi=0$.

3. OW II-AF and its modified model

Juan Zhang [10] superimposed the A-F model and the OW-II model (OW II-AF) to improve the prediction of the uniaxial ratcheting effect of the OW-II model. The formula is proposed as follows

$$
\boldsymbol{\alpha}=\sum_{\mathrm{i}=1}^{M} \boldsymbol{\alpha}_{i}, d \boldsymbol{\alpha}_{i}=\frac{2}{3} r_{i} \gamma_{i} d \varepsilon^{p}-\mu_{\mathrm{i}} \gamma_{i} \boldsymbol{\alpha}_{i} d p-\gamma_{i}\left(\frac{\boldsymbol{\alpha}_{i}}{\mathrm{r}_{i}}\right)^{m_{i}}\left\langle d \lambda_{i}\right\rangle \boldsymbol{\alpha}_{i}
$$

Xiaohui Chen [20] proposed the modified OW II-AF model (M OW II-AF) by superimposing the OW-II model and the A-F model. The kinematic hardening is given by

$$
\boldsymbol{\alpha}=\sum_{i=1}^{M} \boldsymbol{\alpha}_{i}, d \boldsymbol{\alpha}_{i}=\gamma_{i}\left(\frac{2}{3} r_{i} d \varepsilon^{p}-\mu_{i} \phi(p) \boldsymbol{\alpha}_{i} d p-\phi(p)\left(\frac{\overline{\boldsymbol{\alpha}_{i}}}{r_{i}}\right)^{m_{i}}\left\langle d \varepsilon^{p}: \frac{\boldsymbol{\alpha}_{i}}{r_{i} / \phi(p)}\right\rangle \boldsymbol{\alpha}_{i}\right) .
$$

where $\phi(p)$ is cyclic hardening/softening function of materials $\phi(p)=\phi_{\infty}+\left(1-\phi_{\infty}\right) e^{-\omega_{\phi} p}$, and $\phi_{\infty}$ is the stable value of Marquis. 


\subsection{Parameter Determination and Ratchet Simulation of Several Typical Kinematic Hardening Models}

The initial yield stress $\sigma_{0}$ of the material was $120 \mathrm{MPa}$, and the elastic modulus was the slope of the elastic section. By fitting the linear stress-strain curve, the slope was the elastic modulus $E=194 \mathrm{GPa}$. The material parameters $\gamma_{i}$ and $r_{i}$ are determined by the following formula through the uniaxial tension curve.

$$
\mathrm{r}_{i}=\left(\frac{\sigma_{i}-\sigma_{i-1}}{\varepsilon_{i}^{p}-\varepsilon_{i-1}^{p}}-\frac{\sigma_{i+1}-\sigma_{i}}{\varepsilon_{i+1}^{p}-\varepsilon_{i}^{p}}\right) \varepsilon_{i}^{p}, i \neq 1, \gamma_{i}=\frac{1}{\varepsilon_{i}^{p}} .
$$

Finally, $r_{i}$ is obtained by

$$
\sum_{i=1}^{M} r_{i}+\sigma_{0}=\sigma_{\max }
$$

where $\sigma_{i}$ and $\varepsilon_{i}{ }^{p}$ are the stress and plastic strain values corresponding to the endpoints of each section. $\sigma_{0}$ is the stress value when the plastic strain value on the curve is 0 . The number of components that are needed for evaluation of the accuracy of the backstress are set as $M=8$.

The parameters of the models are shown in Table 3.

\begin{tabular}{|c|c|}
\hline Model & Parameter \\
\hline OW-II & $r^{(1-8)} 80,56,69,72,80,61,31,15 \quad \gamma^{(1-8)} 8000,1500,350,180,150,72,65,12$ \\
\hline $\mathrm{AKO}$ & $r^{(1-8)} 90,72,78,60,61,58,34,25 \quad \gamma^{(1-8)} 8000,1500,350,180,150,72,65,12 \mu_{i}=0.2$ \\
\hline AKO IV & $\begin{array}{c}r^{(1-8)} 80,56,69,72,80,61,31,15 \quad \gamma^{(1-8)} 8000,1500,350,180,150,72,65,12 \\
\eta_{01}=0.1, \omega_{1}=5, \eta_{\infty 2}=0.05, \chi=0 \quad \eta_{02}=0.04, \omega_{2}=3, \eta_{\infty 2}=0.03\end{array}$ \\
\hline OWII-AF & $\begin{array}{c}r^{(1-8)} 80,56,69,72,80,61,31,15 \quad \gamma^{(1-8)} 8000,1500,350,180,150,72,65,12 \\
\mu_{i}=0.04, m_{i}=7\end{array}$ \\
\hline M OWII-AF & $\begin{array}{c}r^{(1-8)} 80,56,69,72,80,61,31,15 \gamma^{(1-8)} 8000,1500,350,180,150,72,65 \\
12 m_{i}=7 \eta_{0}=0.04, \omega=8, \eta_{\infty}=0.01, \phi_{\infty}=0.4, \omega_{\phi}=1 \chi=0\end{array}$ \\
\hline
\end{tabular}

Table 3. Parameter determination of different models.

With the incremental loading method in MATLAB, the ratchetting strains were simulated with the above five models for the uniaxial ratcheting experiments discussed in Section 2.2.2. The simulation effects of these models on ratcheting strain of S30408 stainless steel are shown in Figure 5. The simulation of ratcheting strain by these models had low prediction at the early stage of the cycle and over prediction at the later stage of the cycle. The yield platform stress of the material was $580 \mathrm{MPa}$. Therefore, when simulating the ratcheting with a maximum stress of $580 \mathrm{MPa}$, the ratcheting of the material could no longer be accurately obtained through the stress control experimental method. Thus, the ratcheting of the mean stress of $290 \mathrm{MPa}$ and the amplitude stress of $290 \mathrm{MPa}$ will not be discussed further. 


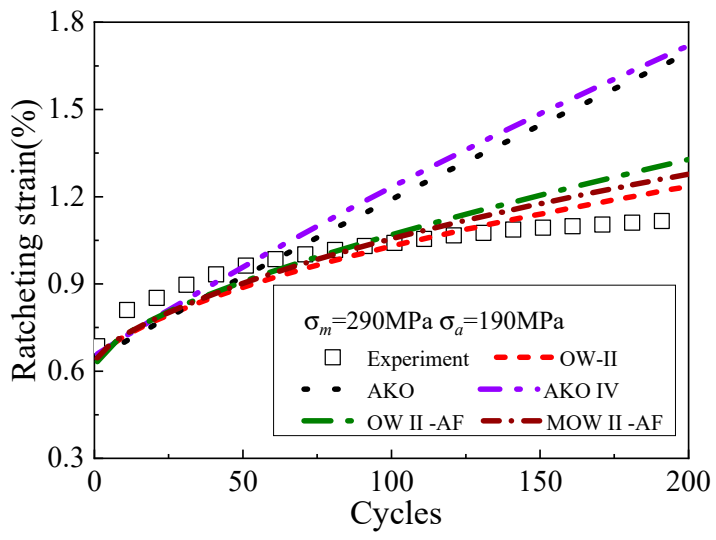

(a)

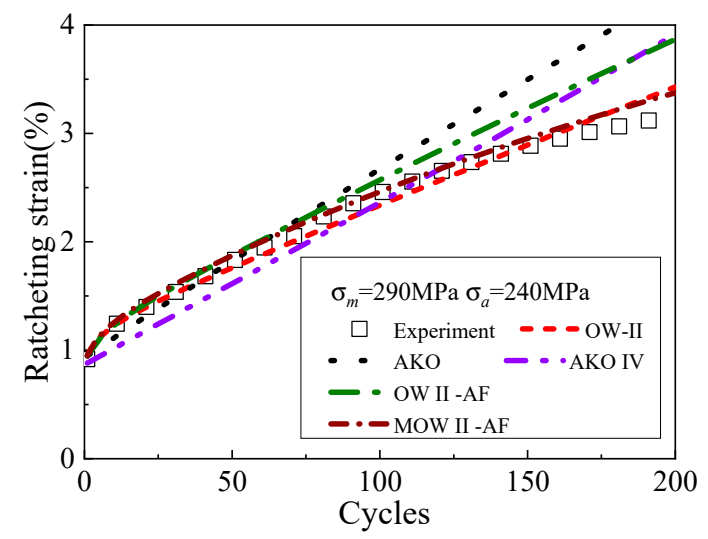

(c)

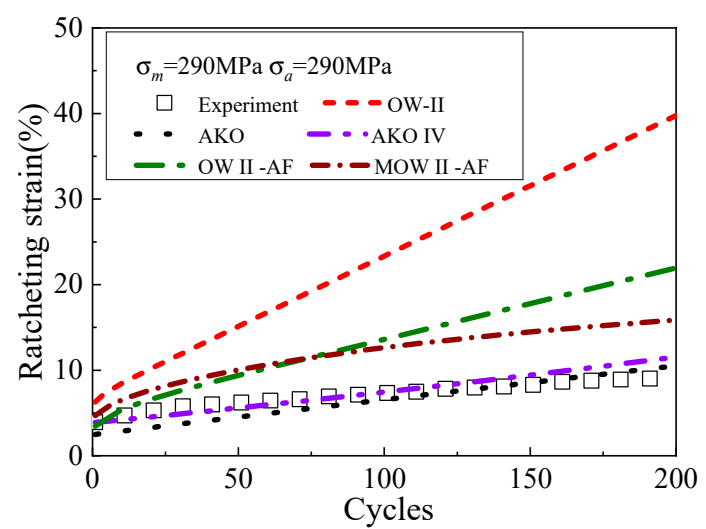

(e)

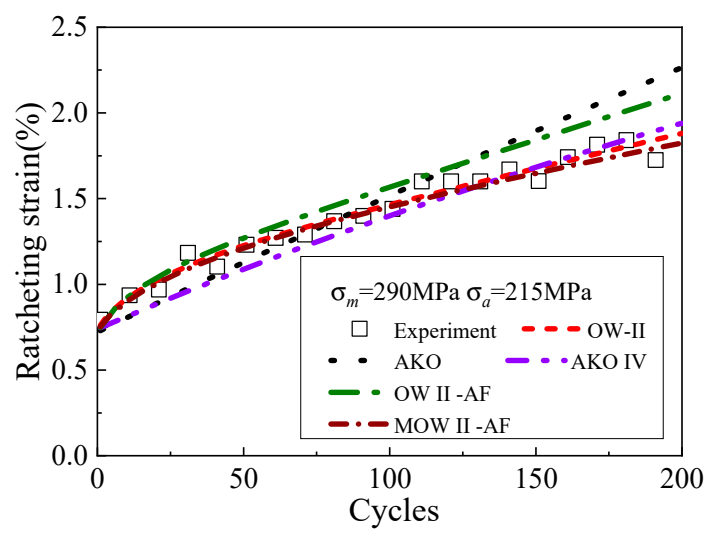

(b)



(d)

Figure 5. Ratcheting strain prediction of different loading conditions: (a) $\sigma_{m}=290 \mathrm{MPa} \sigma_{a}=190 \mathrm{MPa}$ (b) $\sigma_{m}=290 \mathrm{MPa} \sigma_{a}=215 \mathrm{MPa}(\mathbf{c}) \sigma_{m}=290 \mathrm{MPa} \sigma_{a}=240 \mathrm{MPa}$ (d) $\sigma_{m}=240 \mathrm{MPa} \sigma_{a}=240 \mathrm{MPa}$ (e) $\sigma_{m}=290 \mathrm{MPa} \sigma_{a}=290 \mathrm{MPa}$.

\subsection{The Constitutive Model with Martensite Transformation}

The Garion model [30] used the linear mixed hardening model to calculate the backstress. The content of deformed martensite affects the linear kinematic hardening and dynamic recovery term, which can better simulate the secondary hardening phenomenon under uniaxial loading. However, it is difficult to describe the primary hardening phenomenon of materials after they enter plasticity. The accurate simulation of the ratcheting strain depends on the simulation effect of the model on the 
hysteresis loop. As the Garion model cannot describe hysteresis well, it cannot accurately describe the ratcheting strain. However, the description of the content of deformed martensite and its influence on the hardening of the material by this model is worth referencing.

The volume fraction of martensite is the most popular macroscopic internal variable specifying the growth of the martensitic phase $[35,36]$. Bain strain is added to the strain calculation due to the influence of the volume strain caused by the martensitic transformation. The martensite content and cumulative plastic strain values are obtained by experiments, and the evolution law of martensitic content is obtained by fitting the curve. In this paper, the martensite content dependent variable $\xi$ is correlated with the Ohno Wang II model and isotropic hardening model, which can simulate the ratcheting of S30408. We propose the following constitutive model.

1. According to the study of Garion, we assumed that strain $\varepsilon$ is divided into elastic part $\varepsilon^{\mathrm{e}}$ inelastic part $\varepsilon^{p}$ and phase transformation part $\varepsilon^{\text {bs }}$

$$
\varepsilon=\varepsilon^{\mathrm{e}}+\varepsilon^{\mathrm{p}}+\varepsilon^{\mathrm{bs}} .
$$

2. The elastic part obeys Hooke's law

$$
\boldsymbol{\sigma}=\mathbf{E}:\left(\varepsilon-\varepsilon^{p}-\varepsilon^{b s}\right) .
$$

3. The plastic part can be stated as

$$
\mathrm{d} \varepsilon^{p}=\frac{3}{2} \frac{\langle d s \cdot \mathbf{n}\rangle}{h_{s}} \mathbf{n}
$$

4. The martensitic transformation part can be expressed in terms of relative volume change $\Delta v$, due to the phase transformation [29], as

$$
\varepsilon^{\mathrm{bs}}=\frac{1}{3} \Delta v \xi \mathbf{I}=\frac{1}{3} \frac{\left(V_{m}-V_{a}\right)}{V_{a}} \xi \mathbf{I} .
$$

where $V_{a}$ and $V_{m}$ represent the unstresses specific volumes occupied by the austenite and martensite, respectively. The value of $\Delta v$ is approximately $0.02-0.05$, depending on the alloy composition [24].

5. We assumed the material follow von Mises yield criterion, which can be given by

$$
f(\boldsymbol{\sigma}, \boldsymbol{\alpha}, R)=J_{2}(\sigma-\boldsymbol{\alpha})-\sigma_{y}-R
$$

6. The backstress $\alpha$ is altered by the induced martensite, and the evolution law is postulated in the following form:

$$
\begin{gathered}
\boldsymbol{\alpha}=\sum_{i=1}^{M} \boldsymbol{\alpha}_{i} . \\
\mathrm{d} \boldsymbol{\alpha}_{i}=\mathrm{d} \boldsymbol{\alpha}_{i}^{a}+\mathrm{d} \boldsymbol{\alpha}_{i}^{a \xi}=\gamma_{i}\left(\frac{2}{3} r_{i} d \varepsilon^{p}-\left(\frac{\overline{\boldsymbol{\alpha}_{i}}}{r_{i}}\right)^{m_{i}}\left\langle d \varepsilon^{p}: \frac{\boldsymbol{\alpha}_{i}}{\overline{\boldsymbol{\alpha}_{i}}}\right) \boldsymbol{\alpha}_{i}\right)+h \xi \varepsilon^{p} .
\end{gathered}
$$

where $h$ is a parameter that depends on the material and can be determined by trial. Due to the existence of martensite, the backstress increment can be regarded as the sum of pure austensite $\mathrm{d} \boldsymbol{\alpha}_{i}^{a}$ and the interaction between the dislocations into the austenitic matrix and the martensite $\mathrm{d} \boldsymbol{\alpha}_{i}^{a \xi}[29]$.

7. The presence of martensite also affects the cyclic hardening law of materials, and the evolution law is postulated in the following general form:

$$
d R=F(\xi) d p=\left(R_{\infty}(\xi)-R\right) d p .
$$


According to [28], austenitic stainless steel S30408 is characterized by rapid hardening due to martensitic transformation. The martensite content of the material increases rapidly with the increase of cumulative plastic strain, and then tends to be stable. The occurrence of martensite transformation has a certain influence on the cyclic hardening of the material, which can be attributed to isotropic hardening.

$$
\mathrm{d} R=\frac{2}{3}(1-\xi) b(Q \xi-R) d p .
$$

where $R$ is the isotropic hardening parameter, and $p$ is the cumulative plastic strain. The term $(1-\xi)$ is added to compensate for the assumption that the martensite is elastic [29]. In reality, the martensite shall rather be considered elasto-plastic. Therefore, the contribution to the hardening of the material is slightly smaller.

8. According to [28], the evolution law of the martensite content of S30408 austenitic stainless steel at $110 \mathrm{~K}$ presents a trend of rapid increase at first and then stability, which can be expressed as follows.

$$
\mathrm{d} \xi=\omega_{m}\left(\xi_{\infty}-\xi\right) d p
$$

By changing the rate of reaching the saturation value $\omega_{m}$, the value of deformation induced martensite due to the cumulative plastic strain can be controlled. $\omega_{m}$ is mainly influenced by the temperature, the loading rate, etc., which requires further investigations.

\subsection{Determination of Constitutive Model Parameters}

In addition to the parameters in the Ohno-Wang model determined above, the model parameters related to the martensitic transformation can be determined as follows.

Cryogenic temperature torsion experiments were performed on specimens with a torque amplitude of $2.5 \mathrm{Nm}$ and a cycle of $3 \mathrm{~s}$ [37]. It can be seen from Figure 6 that $\mathrm{S} 30408$ austenitic stainless steel showed rapid cyclic hardening in the first 10 cycles, and then the hardening rate decreased until 200 cycles. The maximum angular amplitude was approximately twice that of the stable angle. Therefore, S30408 is a cyclic hardening material at $110 \mathrm{~K}$, and tends to be stable when the number of cycles exceeds 200 .

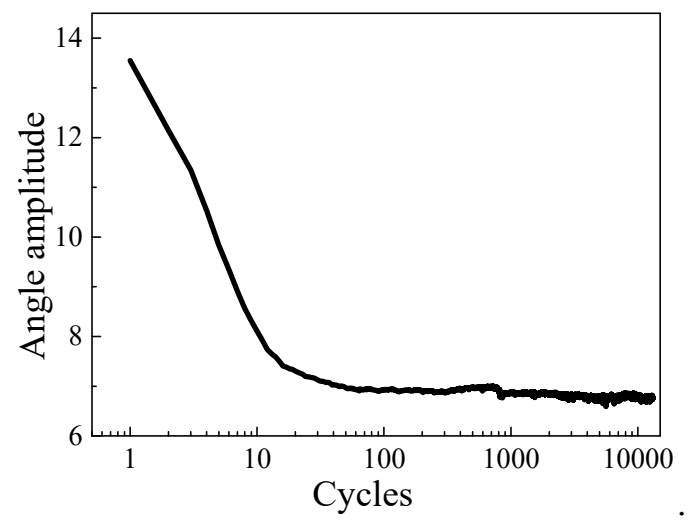

Figure 6. Angular amplitude vs. cycles.

In this study, the cyclic hardening properties of S30408 austenitic stainless steel are all attributed to isotropic hardening. According to the isotropic hardening rule, the peak stress and accumulated plastic strain of the symmetric strain cycle meet the requirement

$$
\sigma_{\text {peak }}=\sigma-Q \xi[1-\exp (-b p)]
$$


where $\sigma_{\text {peak }}$ is the peak stress. As shown in Figure 7a, the isotropic parameters $\mathrm{C}$ and $\mathrm{Q}$ can be obtained by fitting the peak stress and cumulative plastic strain. The parameters related to the martensitic transformation are obtained by fitting the martensite content and cumulative plastic strain curve, as shown in Figure $7 \mathrm{~b}$, and the saturation value of the martensite content $\xi_{\infty}=0.9$, which is influenced by the temperature. Parameter $\omega_{m}$ is determined by trial at present, as shown in Figure 7c. The material parameters of the model are presented in Table 4.

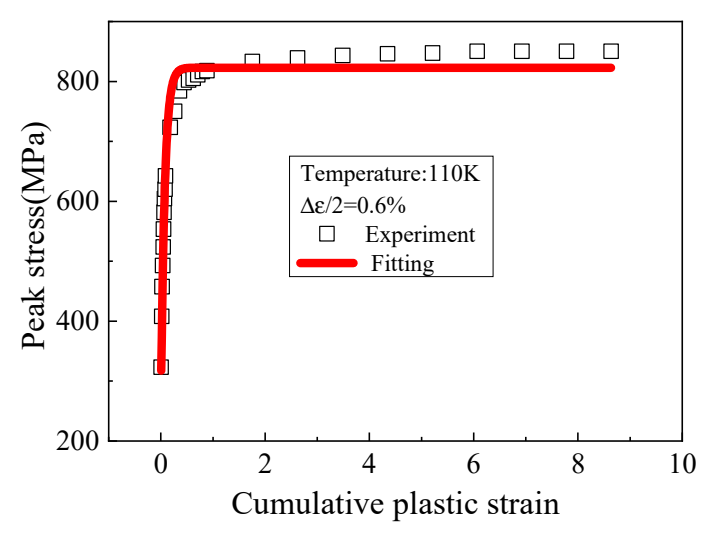

(a)

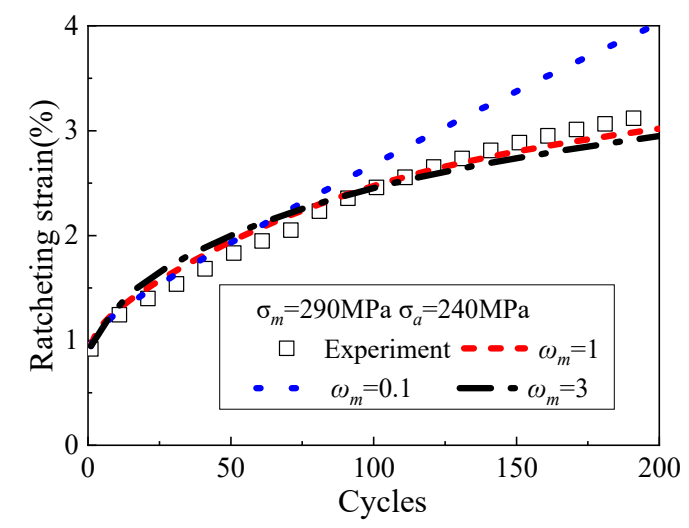

(c)

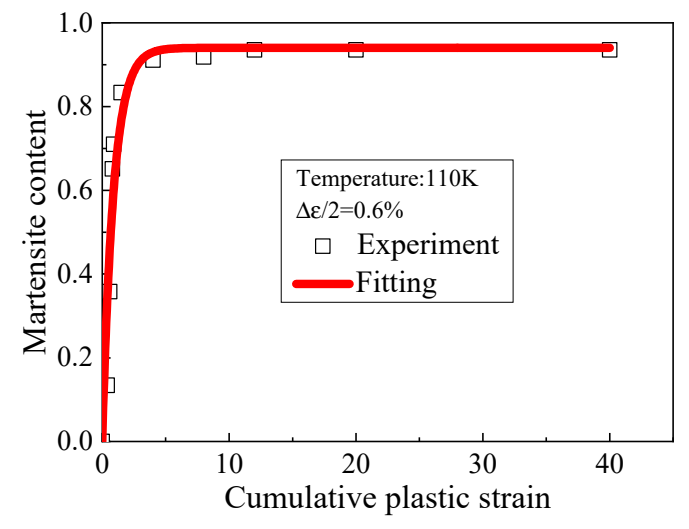

(b)

Figure 7. Parameter determination of the constitutive model: (a) isotropic hardening, (b) martensite transformation, (c) determination of parameter $\omega_{m}$.

Table 4. Material parameters of the constitutive model.

\begin{tabular}{ccc}
\hline Style & \multicolumn{2}{c}{ Parameter } \\
\hline Uniaxial Tension & $r^{(1-8)} 80,56,69,72,80,61,31,15$ & $\gamma^{(1-8)} 8000,1500,350,180,150,72,65,12$ \\
Uniaxial Ratchet & & $m_{i}=7$ \\
Martensite Content & $\Delta v=0.05 \quad h=0.1 \quad \begin{array}{l}\omega_{m}=1 \quad \xi_{0}=0.03 \quad \xi_{\infty}=0.9 \\
\text { Isotropic Hardening }\end{array}$ \\
\hline$=560 \quad b=10$
\end{tabular}

\subsection{Model Prediction Results}

With the incremental loading method by MATLAB, the uniaxial tension and uniaxial ratchetting behavior were simulated. With the material parameters determined above, it can be seen from Figure 8 that the model has a good fit for the uniaxial tension curve of the material. 


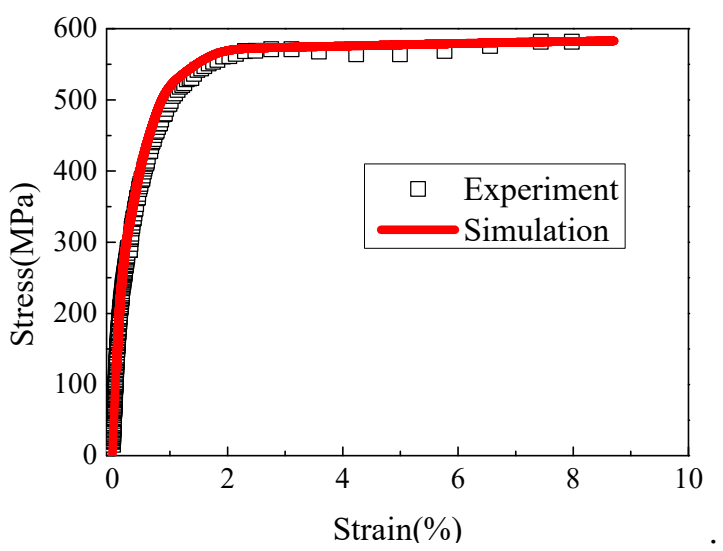

Figure 8. Simulation of uniaxial tension.

From Figure 9, the predicted stress-strain response of this constitutive model is not greatly different from the experimental value, and the stress-strain response of different loading conditions can be reasonably predicted.



(a)

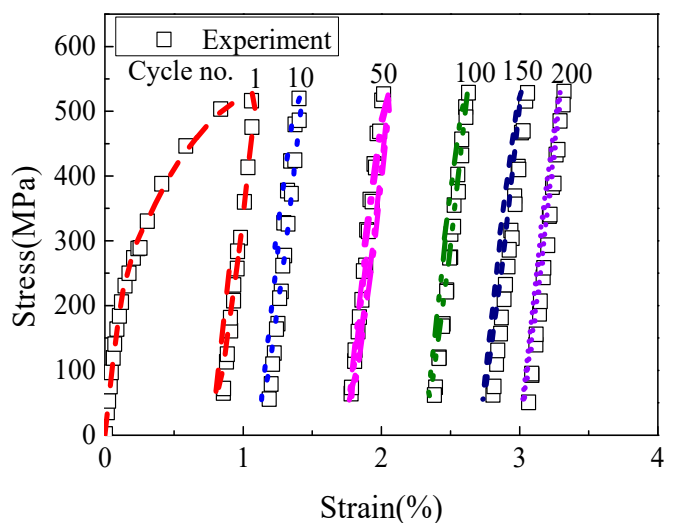

(c)

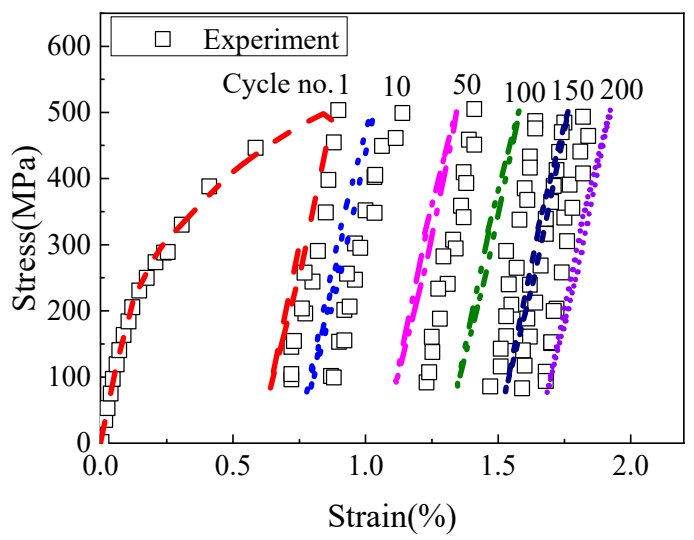

(b)

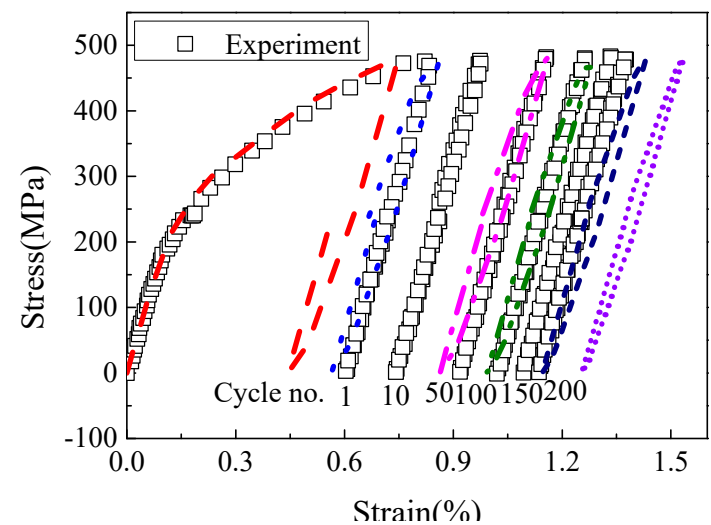

(d)

Figure 9. Simulation and experiment values of stress-strain response: (a) $\sigma_{m}=290 \mathrm{MPa} \sigma_{a}=190 \mathrm{MPa}$ (b) $\sigma_{m}=290 \mathrm{MPa} \sigma_{a}=215 \mathrm{MPa}(\mathbf{c}) \sigma_{m}=290 \mathrm{MPa} \sigma_{a}=240 \mathrm{MPa}$ (d) $\sigma_{m}=240 \mathrm{MPa} \sigma_{a}=240 \mathrm{MPa}$.

It can be seen from Figure 10 that the ratcheting strain predictions are quite effective for the load case with a mean stress of $290 \mathrm{MPa}$ and amplitude stress of $240 \mathrm{MPa}$ and for the load case with a mean stress of $290 \mathrm{MPa}$ and amplitude stress of $215 \mathrm{MPa}$. The predictions are a little higher for the other two load cases, which are further from the load case used for the model parameter determination. 
However, this does overcome the disadvantages of early lower prediction and later over prediction by other models. Although there is little difference between the Ohno-Wang II model and the proposed model in predicting uniaxial ratcheting strain, the Ohno-Wang II model always overpredicts ratcheting strain in late cycles, and is not as effective as the proposed model. This is because the body centered tetragonal martensite is much harder than the face centered cubic austenite, which can improve the hardness of materials. It is necessary to consider the martensitic transformation.



Figure 10. The ratcheting strain under different working conditions by the proposed model.

As the experiments were conducted at cryogenic temperatures, to observe any change of martensite content at any time was not convenient. Therefore, by measuring the content of the deformation-induced martensite after the experiments and comparing it with the simulated values, the deviation between the predicted value of martensite content and the experimental value can be observed in Figure 11, within the acceptable range. Therefore, we considered that the model could reasonably predict the content of the deformation induced martensite at cryogenic temperatures.

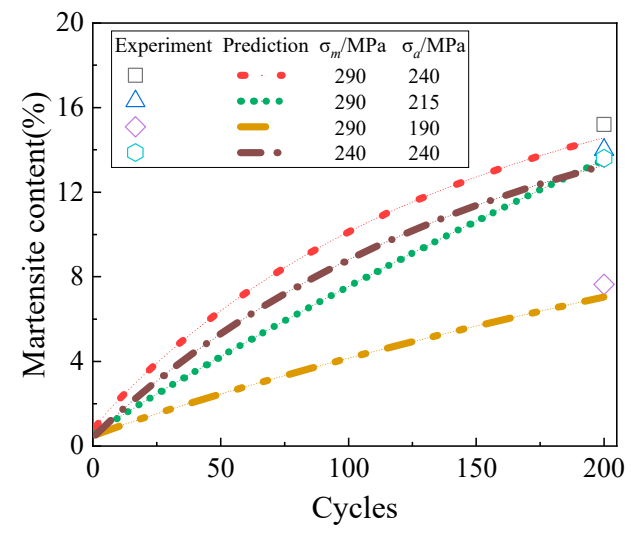

Figure 11. Martensite content prediction under different loading conditions by the proposed model.

\section{Finite Element Implementations}

In this section, we detail the finite element implementation of the proposed model with martensitic transformation. In general, the nonlinear equation is solved by Newton-Raphson (N-R) iteration (Figure 12) for every load step, such as $\sigma_{1}$ and $\sigma_{2}$, in which the trial strain increment is determined by the consistent tangent matrix. However, in the local N-R iteration, namely from each tangential prediction point back to the yield surface, we used the substitution method, namely the radial backward substitution (Figure 13). 


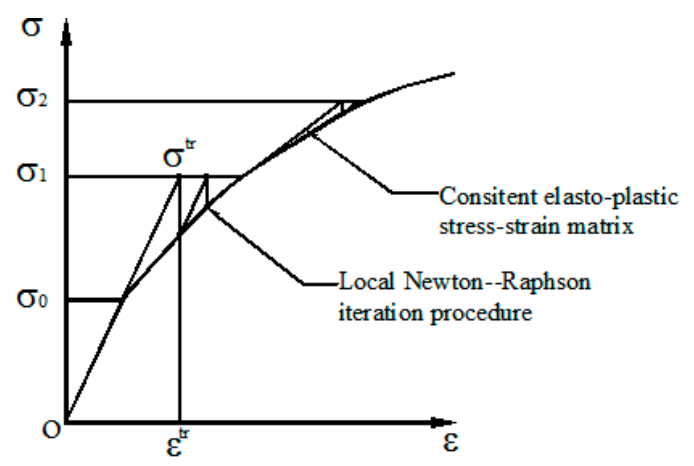

Figure 12. Sketch of the Newton-Raphson (N-R) iteration.

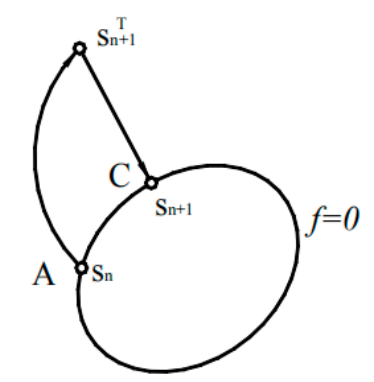

Figure 13. Sketch of the radial return method.

4.1. The Basic Equation of Cyclic Plasticity Constitutive Model with Martensite Transformation

1. If the material obeys von Mises yield criterion, the yield function of the material is

$$
f=\frac{3}{2}(\mathbf{s}-\boldsymbol{\alpha})^{T}\left[M_{1}\right](s-\boldsymbol{\alpha}) .
$$

2. Plasticity flow rule

$$
\mathrm{d} \varepsilon^{p}=\frac{3}{2} \frac{\langle d s \cdot \mathbf{n}\rangle}{h_{s}} \mathbf{n}
$$

3. Kinematic hardening law

$$
\begin{gathered}
\boldsymbol{\alpha}=\sum_{i=1}^{M} \boldsymbol{\alpha}_{i} . \\
\mathrm{d} \boldsymbol{\alpha}_{i}=\gamma_{i}\left(\frac{2}{3} r_{i} d \varepsilon^{p}-\left(\frac{\overline{\boldsymbol{\alpha}}_{i}}{r_{i}}\right)^{m_{i}}\left\langle d \varepsilon^{p}: \frac{\boldsymbol{\alpha}_{i}}{\overline{\boldsymbol{\alpha}_{i}}}\right\rangle \boldsymbol{\alpha}_{i}\right)+h \xi^{p} .
\end{gathered}
$$

4. Isotropic hardening rule

$$
\begin{gathered}
\sigma_{y}=\sigma_{y}^{0}+R . \\
\mathrm{d} R=\frac{2}{3}(1-\xi) b(Q \xi-R) d p .
\end{gathered}
$$

5. Evolution of the martensite content

$$
\mathrm{d} \xi=\omega_{m}\left(\xi_{\infty}-\xi\right) d p
$$

4.2. Solution of Plastic Strain by Euler Backward Method

Given all constitutive variables at $t=t_{n}$, the convergent solutions contain $\sigma_{n}, \boldsymbol{\alpha}_{n}, \varepsilon_{n}^{p}, \varepsilon_{n}^{b s}, \xi_{n}$, and $R_{n}$. 
The elastic tentative stress:

$$
\boldsymbol{\sigma}_{\mathrm{n}+1}^{T}=\mathbf{D}^{e}: \varepsilon_{n+1}^{T} .
$$

The tentative strain:

$$
\varepsilon_{\mathrm{n}+1}^{T}=\varepsilon_{n+1}-\varepsilon_{n}^{p}-\varepsilon_{n}^{b s} .
$$

Due to the elastic isotropy and plastic incompressibility, taking the deviatoric part of tentative stress $\boldsymbol{\sigma}_{n+1}^{T}$

$$
\mathbf{S}_{n+1}^{T}=\sigma_{n+1}^{T}-\frac{1}{3} \operatorname{tr}\left(\boldsymbol{\sigma}_{n+1}^{T}\right) \mathbf{I}_{s} .
$$

According to the radial return algorithm [38], the deviatoric stress on the yield surface corresponds to the tentative deviatoric stress

$$
\mathbf{S}_{n+1}=S_{n+1}^{T}-2 G\left[M_{2}\right]\left(\Delta \varepsilon_{n+1}^{p}+\Delta \varepsilon_{n+1}^{b s}\right) .
$$

Bain strain increment $\Delta \varepsilon_{n+1}^{b s}$

$$
\Delta \varepsilon_{n+1}^{b s}=\frac{1}{3} \Delta v \cdot \Delta \xi_{n+1} \mathbf{I}_{\mathbf{s}} .
$$

Martensite content $\Delta \xi_{n+1}$

$$
\Delta \xi_{n+1}=\omega_{m}\left(\xi_{\infty}-\xi_{n}\right) \Delta p_{n+1} .
$$

Isotropic hardening variable $\Delta R_{n+1}$

$$
\Delta R_{n+1}=\frac{2}{3}\left(1-\Delta \xi_{n+1}\right) b\left(Q \Delta \xi_{n+1}-R_{n}\right) \Delta p_{n+1} .
$$

Normal direction of the yield surface

$$
\mathbf{n}_{n+1}=\frac{\mathbf{S}_{n+1}-\mathbf{n}_{n+1}}{\left\|\mathbf{S}_{n+1}-\mathbf{n}_{n+1}\right\|}=\sqrt{\frac{3}{2}} \frac{\mathbf{S}_{n+1}-\mathbf{n}_{n+1}}{\sigma_{y(n+1)}} \Delta p_{n+1} .
$$

If the yield surface function is $f_{n+1}=0$, the plastic strain increment can be calculated by the following formula

$$
\Delta \varepsilon_{\mathrm{n}+1}^{p}=\sqrt{\frac{3}{2}} \Delta p\left[M_{1}\right] \mathbf{n}_{n+1}=\frac{3}{2} \frac{\mathbf{S}_{n+1}-\mathbf{n}_{n+1}}{\sigma_{y(n+1)}} \Delta p_{n+1} .
$$

Plastic multiplier in the martensitic transformation model can be derived as follows:

$$
\begin{gathered}
\boldsymbol{\alpha}_{n+1}=\boldsymbol{\alpha}_{n}+\sum_{i=1}^{M} \Delta \boldsymbol{\alpha}_{n+1}^{(i)} . \\
\Delta \boldsymbol{\alpha}_{n+1}^{(i)}=\frac{2}{3} r_{i} \gamma_{i}\left[M_{2}\right] \Delta \varepsilon_{n+1}^{p}+\frac{2}{3} r_{i} \gamma_{i} h \Delta \xi_{n+1}\left[M_{2}\right] \Delta \varepsilon_{n+1}^{p}-\gamma_{i}\left(\overline{\frac{\boldsymbol{\alpha}_{n+1}^{(i)}}{r_{i}}}\right)^{m_{i}}\left\langle\Delta \varepsilon_{n+1}^{p}: \frac{\boldsymbol{\alpha}_{n+1}^{(i)}}{\overline{\boldsymbol{\alpha}_{n+1}^{(i)}}}\right\rangle \boldsymbol{\alpha}_{n+1}^{(i)} . \\
\boldsymbol{\alpha}_{n+1}^{(i)}=\boldsymbol{\alpha}_{n}^{(i)}+\frac{2}{3} r_{i} \gamma_{i}\left[M_{2}\right] \Delta \varepsilon_{n+1}^{p}+\frac{2}{3} r_{i} \gamma_{i} h \Delta \xi_{n+1}\left[M_{2}\right] \Delta \varepsilon_{n+1}^{p}-\gamma_{i}\left(\overline{\frac{\boldsymbol{\alpha}_{n+1}^{(i)}}{r_{i}}}\right)^{m_{i}}\left\langle\Delta \varepsilon_{n+1}^{p}: \frac{\boldsymbol{\alpha}_{n+1}^{(i)}}{\overline{\boldsymbol{\alpha}_{n+1}^{(i)}}}\right\rangle \boldsymbol{\alpha}_{n+1}^{(i)} . \\
\boldsymbol{\alpha}_{n+1}^{(i)}=\theta_{n+1}^{(i)}\left(\boldsymbol{\alpha}_{n}^{(i)}+\frac{2}{3} r_{i} \gamma_{i} \Delta p_{n+1}\left[M_{1}\right] \mathbf{n}_{n+1}+\frac{2}{3} r_{i} \gamma_{i} \Delta p_{n+1} h \Delta \xi_{n+1}\left[M_{1}\right] \mathbf{n}_{n+1}\right) .
\end{gathered}
$$




$$
\theta_{n+1}^{(i)}=\frac{1}{1+\gamma_{i}\left(\overline{\frac{\boldsymbol{\alpha}_{n+1}^{(i)}}{r_{i}}}\right)^{m_{i}}\left\langle\mathbf{n}_{n+1}: \frac{\boldsymbol{\alpha}_{n+1}^{(i)}}{\overline{\boldsymbol{\alpha}_{n+1}^{(i)}}}\right\rangle \Delta p_{n+1}}
$$

The yield function is:

$$
f_{y}^{\text {trial }}=\frac{3}{2}(\mathbf{s}-\boldsymbol{\alpha})^{T}\left[M_{1}\right](\mathbf{s}-\boldsymbol{\alpha})-\left(\sigma_{y(n+1)}-R_{\mathrm{n}+1}\right) .
$$

If $f_{y}^{\text {trial }} \leq 0$, the material does not yield at this strain increment, $\boldsymbol{\sigma}_{n+1}=\boldsymbol{\sigma}_{n+1}^{T}$.

If $f_{y}^{\text {trial }}>0$, the material yields and enters into the plastic state. Under this strain increment condition, there is:

$$
\boldsymbol{\sigma}_{\mathrm{n}+1}=\boldsymbol{\sigma}_{n+1}^{T}-\mathbf{D}^{e}: \Delta \varepsilon_{n+1}^{p} .
$$

Equation (41) subtracted from Equation (32) gives

$$
\mathbf{S}_{n+1}-\boldsymbol{\alpha}_{n+1}=\mathbf{S}_{n+1}^{T}-2 G\left[M_{2}\right]\left(\Delta \varepsilon_{n+1}^{p}+\Delta \varepsilon_{n+1}^{b s}\right)-\sum_{i=1}^{M} \theta_{n+1}^{(i)}\left(\boldsymbol{\alpha}_{n}^{(i)}+\frac{2}{3} r_{i} \gamma_{i}\left(h \Delta \xi_{n+1}+1\right)\left[M_{2}\right] \Delta \varepsilon_{n+1}^{p}\right) .
$$

Substitution of Equation (37) into Equation (44) provides

$$
\mathbf{S}_{n+1}-\boldsymbol{\alpha}_{n+1}=\frac{\left(\mathbf{S}_{n+1}^{T}-2 G\left[M_{2}\right] \Delta \varepsilon_{n+1}^{b s}-\sum_{i=1}^{M} \theta_{n+1}^{(i)} \boldsymbol{\alpha}_{n}^{(i)}\right)}{\left(1+3 G \Delta p_{n+1} / \sigma_{y(n+1)}-\sum_{i=1}^{M} r_{i} \gamma_{i}\left(h \Delta \xi_{n+1}+1\right) \theta_{n+1}^{(i)} \Delta p_{n+1} / \sigma_{y(n+1)}\right)}
$$

$\mathbf{S}_{n+1}-\boldsymbol{\alpha}_{n+1}$ satisfies yield function, thus the following formula can be obtained:

$$
\Delta \mathrm{p}=\frac{\left[\frac{3}{2}\left(\mathbf{S}_{n+1}^{T}-2 G\left[M_{2}\right] \Delta \varepsilon_{n+1}^{b s}-\sum_{i=1}^{M} \theta_{n+1}^{(i)} \boldsymbol{\alpha}_{n}^{(i)}\right)^{T}\left[M_{1}\right]\left(S_{n+1}^{T}-2 G\left[M_{2}\right] \Delta \varepsilon_{n+1}^{b s}-\sum_{i=1}^{M} \theta_{n+1}^{(i)} \boldsymbol{\alpha}_{n}^{(i)}\right)\right]^{\frac{1}{2}}-\sigma_{y(n+1)}}{3 G+\sum_{i=1}^{M} r_{i} \gamma_{i}\left(h \Delta \xi_{n+1}+1\right) \theta_{n+1}^{(i)}} .
$$

When plastic multipliers meet the following limitations, the results converge

$$
|\Delta p(k+1)-\Delta p(k)| \leq e p s .
$$

The following formulas can be obtained when the iterative calculation converges

$$
\begin{gathered}
\Delta \varepsilon_{n+1}^{\mathrm{p}}=\Delta p(k+1) \sqrt{\frac{3}{2}}\left[M_{1}\right] \mathbf{n}_{n+1} . \\
\Delta \varepsilon_{n+1}^{b s}=\frac{1}{3} \Delta v \cdot \Delta \xi_{n+1} \mathbf{I}_{\mathrm{s}} . \\
\Delta \xi_{\mathrm{n}+1}=\omega_{\mathrm{m}}\left(\xi_{\infty}-\xi_{n}\right) \Delta p_{n+1} . \\
\boldsymbol{\sigma}_{\mathrm{n}+1}=\mathbf{D}^{\mathrm{e}}:\left(\varepsilon_{n+1}^{\mathrm{tr}}-\Delta \varepsilon^{p}\right)-\varepsilon^{b s} . \\
\varepsilon_{n+1}^{p}=\varepsilon_{n}^{p}+\Delta \varepsilon_{n+1}^{\mathrm{p}} . \\
\varepsilon_{n+1}=\varepsilon_{n+1}^{e}+\varepsilon_{n+1}^{p}+\varepsilon_{n+1}^{b s} . \\
\Delta R_{n+1}=\frac{2}{3}\left(1-\Delta \xi_{n+1}\right) b\left(Q \Delta \xi_{n+1}-R_{\mathrm{n}}\right) \Delta p_{n+1} . \\
R_{n+1}=R_{\mathrm{n}}+\Delta R_{n+1} .
\end{gathered}
$$




$$
\sigma_{y(n+1)}=\sigma_{\mathrm{y}}^{0}+R_{n+1} .
$$

The above process is represented by a flow chart in Figure 14 .

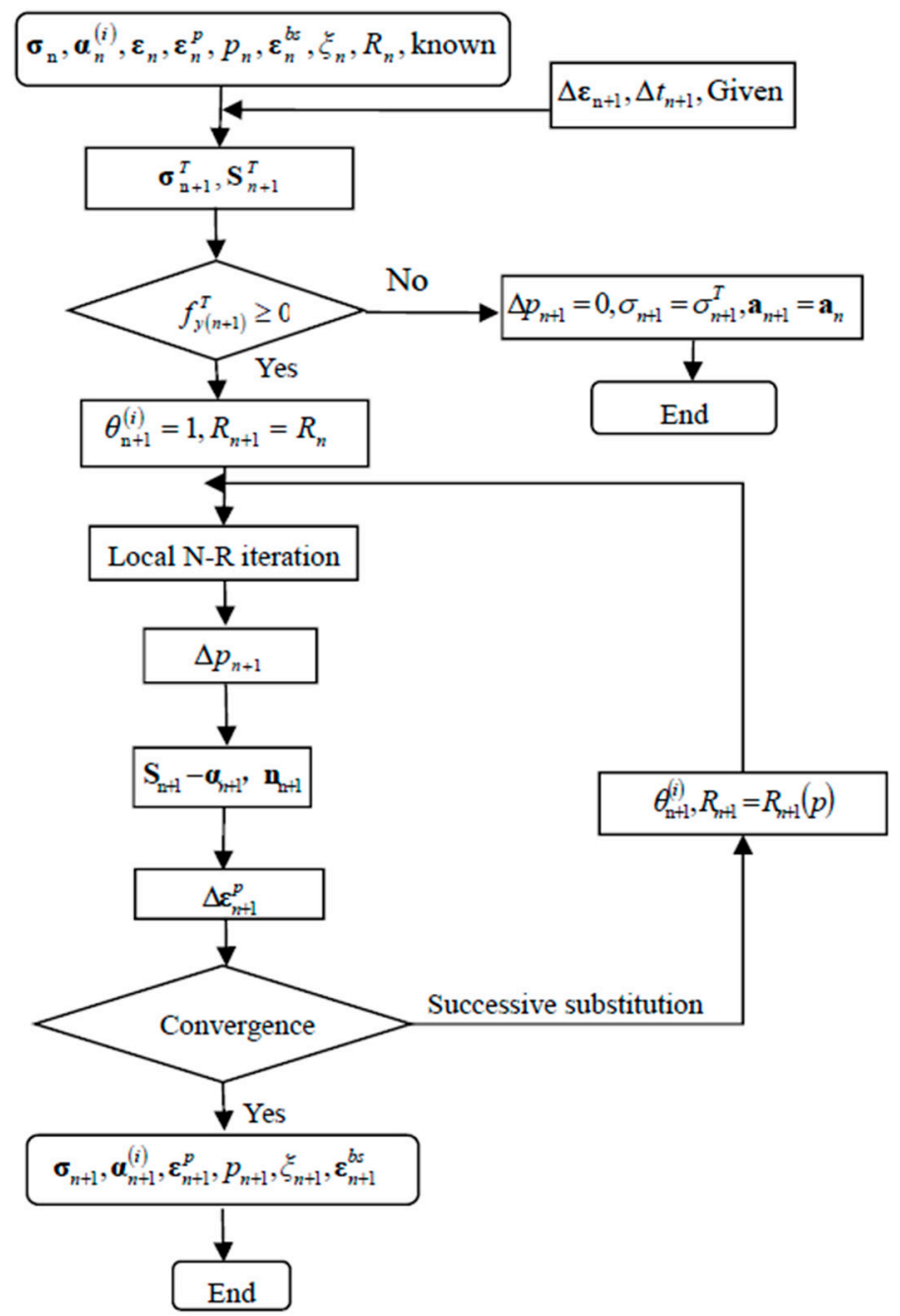

Figure 14. Flow diagram of the proposed model.

\subsection{Consistent Tangent Modulus and Calculation of Strain Increment}

The consistent tangent modulus [39], $\mathrm{d} \Delta \boldsymbol{\sigma}_{n+1} / \mathrm{d} \Delta \boldsymbol{\varepsilon}_{n+1}$, is calculated for the martensitic transformation constitutive model.

$$
\begin{gathered}
\frac{\mathrm{d} \Delta \boldsymbol{\sigma}_{n+1}}{d \Delta \varepsilon_{n+1}}=\mathbf{D}^{e}-4 G^{2} \mathbf{L}_{n+1}^{-1}: \mathbf{I}_{d} . \\
L_{n+1}=2 G \mathbf{I}+\sum_{i=1}^{M} \mathbf{H}_{n+1}^{(i)}+\frac{2}{3}\left(\frac{d Y}{d p}\right)_{n+1} \mathbf{n}_{n+1} \otimes \mathbf{n}_{n+1}+\frac{2}{3} \frac{Y_{n+1}}{\Delta p_{n+1}}\left(\mathbf{I}-\mathbf{n}_{n+1} \otimes n_{\mathbf{n}+1}\right) . \\
\mathrm{d} \boldsymbol{\alpha}_{n+1}^{(i)}=\frac{2}{3} r_{i} \gamma_{i}(1+h \xi) \theta_{n+1}^{(i)}\left[M_{2}\right] d \Delta \varepsilon_{n+1}^{p}+\frac{d \theta_{n+1}^{(i)}}{\theta_{n+1}^{(i)}} \boldsymbol{\alpha}_{n+1}^{(i)} .
\end{gathered}
$$

To obtain $\mathbf{H}_{n+1}^{(i)}$, we use the differentiating Equation (41). 
Differentiation Equation (42) and combined with Equation (37), $\mathrm{d} \theta_{n+1}^{(i)}$, can be expressed by

$$
\mathrm{d} \theta_{n+1}^{(i)}=-\sqrt{\frac{2}{3}} \theta_{n+1}^{(i)^{2}} \gamma_{i}\left(\overline{\frac{\boldsymbol{\alpha}_{n+1}^{(i)}}{r_{i}}}\right)^{m_{i}}\left\langle\mathbf{n}_{n+1}^{T}: \frac{\boldsymbol{\alpha}_{n+1}^{(i)}}{\overline{\boldsymbol{\alpha}_{n+1}^{(i)}}}\right\rangle: \mathrm{d} \Delta \varepsilon_{n+1}^{p} .
$$

The substitution of Equation (61) into Equation (60) provides

$$
\mathrm{d} \boldsymbol{\alpha}_{n+1}^{(i)}=\frac{2}{3} r_{i} \gamma_{i} \theta_{n+1}^{(i)}\left(\left[M_{2}\right](1+h \xi)-\mathbf{m}_{n+1}^{(i)}\left(\overline{\frac{\boldsymbol{\alpha}_{n+1}^{(i)}}{r_{i}}}\right)^{m_{i}}\left(\mathbf{m}_{n+1}^{(i)}\right)^{T}\right): \mathbf{d} \Delta \varepsilon_{n+1}^{p}
$$

where

or

$$
\mathbf{m}_{n+1}^{(i)}=\sqrt{\frac{3}{2}} \frac{\boldsymbol{\alpha}_{n+1}^{(i)}}{r_{i}}
$$

$$
\mathbf{m}_{n+1}^{(i)}=\sqrt{\frac{3}{2}} \frac{\boldsymbol{\alpha}_{n+1}^{(i)}}{\overline{\boldsymbol{\alpha}_{n+1}^{(i)}}} \overline{\boldsymbol{\alpha}_{n+1}^{(i)}}=\sqrt{\frac{3}{2}\left\{\boldsymbol{\alpha}_{n+1}^{(i)}\right\}^{T}\left[M_{1}\right]\left\{\boldsymbol{\alpha}_{n+1}^{(i)}\right\}} .
$$

The constitutive model, $\mathbf{H}_{n+1}^{(i)}$, with martensitic transformation can be calculated by the following formula.

$$
\mathbf{H}_{n+1}^{(i)}=\frac{d \boldsymbol{\alpha}_{n+1}^{(i)}}{d \Delta \boldsymbol{\varepsilon}_{n+1}^{p}}=\frac{2}{3} r_{i} \gamma_{i} \theta_{n+1}^{(i)}\left(\left[M_{2}\right](1+h \xi)-\left(\frac{\overline{\boldsymbol{\alpha}_{n+1}^{(i)}}}{r_{i}}\right)^{m_{i}}\left\langle\mathbf{n}_{n+1}^{T}: \frac{\boldsymbol{\alpha}_{n+1}^{(i)}}{\overline{\boldsymbol{\alpha}_{n+1}^{(i)}}}\right\rangle\right)
$$

The substitution of Equation (23) into Equation (39) provides

$$
\mathrm{d} \boldsymbol{\alpha}_{n+1}^{(i)}=(1+h \xi) r_{i} \gamma_{i} \frac{\mathrm{d} \mathbf{s} \cdot \mathbf{n}_{n+1}}{h_{s}} \mathbf{n}_{n+1}-\gamma_{i}\left(\frac{\overline{\boldsymbol{\alpha}_{n+1}^{(i)}}}{r_{i}}\right)^{m_{i}}\left\langle n_{n+1}^{T}: \frac{\boldsymbol{\alpha}_{n+1}^{(i)}}{\overline{\boldsymbol{\alpha}_{n+1}^{(i)}}}\right\rangle \boldsymbol{\alpha}_{n+1}^{(i)} \mathrm{d} p .
$$

The expression of $h_{\mathrm{s}}$, in the martensitic transformation model, can be obtained by the method provided in [40].

$$
\begin{gathered}
Y=\sigma_{y}=\sigma_{y}^{0}+R . \\
h_{s}=\sum_{i=1}^{M} \gamma_{i} \gamma_{i}(1+h \xi)-\sqrt{\frac{3}{2}} \mathbf{n}_{n+1}^{T}\left[M_{1}\right] \sum_{i=1}^{M} \gamma_{i} \boldsymbol{\alpha}_{n+1}^{(i)}\left\langle\mathbf{n}_{n+1}^{T}: \frac{\boldsymbol{\alpha}_{n+1}^{(i)}}{\boldsymbol{\alpha}_{n+1}^{(i)}}\right\rangle+\frac{\partial \sigma_{y}}{\partial p} . \\
\mathrm{d} R=\frac{2}{3}(1-\xi) b(Q \xi-R) d p . \\
\mathrm{d} \xi=\omega_{m}\left(\xi_{\infty}-\xi\right) d p .
\end{gathered}
$$

Thus, the nonlinear numerical calculation of the constitutive model with martensitic transformation can be realized.

\subsection{Embedment of Constitutive Model in the ANSYS Program and Ratchetting Prediction}

The constitutive model with the martensitic transformation was embedded in ANSYS to form the user's ANSYS executive file by compiling and connecting the subroutine userspl.f of ANSYS. The programming was verified by the uniaxial tension and used to predict the ratchetting strain for uniaxial loading. 


\subsubsection{Uniaxial Tension Verification}

Based on the proposed model, the uniaxial tensile behavior of the material was calculated using the user version of ANSYS. For simplicity, only one element PLANE42 with a side length of 1 was used for the calculation, as shown in Figure 15. The x-direction displacement constraint was applied to the left side of the model, the y-direction displacement constraint was applied to the lower side, and the $\mathrm{x}$-direction load was applied to the right side.

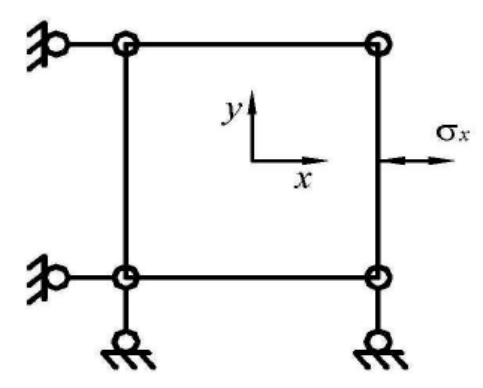

Figure 15. Uniaxial tension of the FEA model.

The predictions of the uniaxial tension are plotted in Figure 16 together with those predicted by the incremental loading method of MATLAB. The comparison results show that the results of the finite element method with a single element were consistent with the experimental results and MATLAB predicted results.

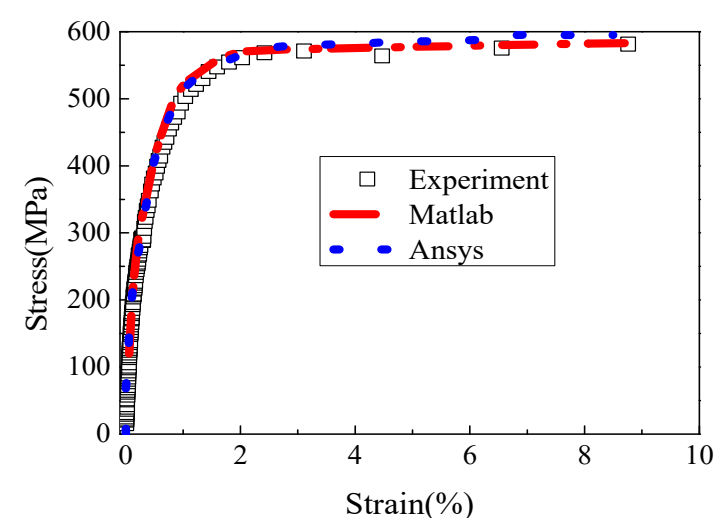

Figure 16. Uniaxial tensile verification curve.

\subsubsection{Uniaxial Ratcheting Prediction}

We simulated the ratcheting strains of the specimen under four different uniaxial loading conditions, first taking the mean stress of $290 \mathrm{MPa}$ and the amplitude stress of $240 \mathrm{MPa}$ as an example. The finite element model of the specimen was established with element SOLID45. In the finite element model, the bottom surface was fully constrained, and the axial load of 353-3746 N was cyclic and applied on the master node of the rigid region for the top surface. Figure 17 indicates the boundary condition of the finite element model. The cyclic loading will generate a uniform cyclic stress of 50-530 MPa in the measuring cross section of the specimen. 


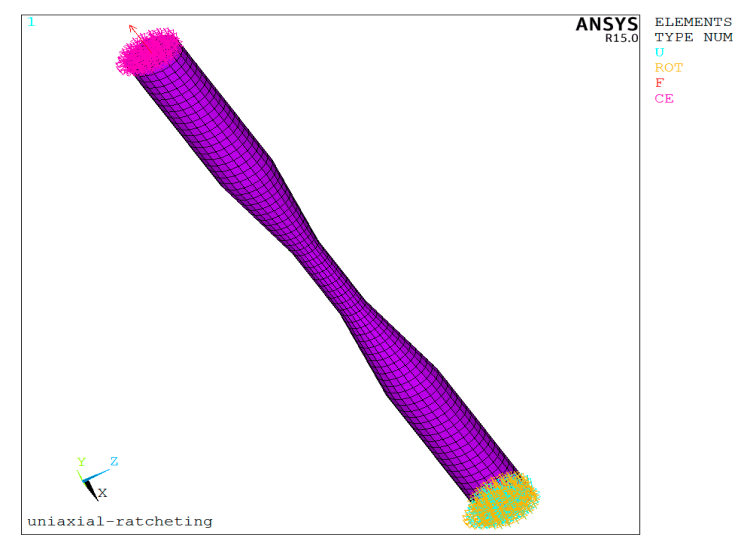

Figure 17. Boundary conditions applied to the specimen finite element model.

As shown in Figure 18, the maximum plastic strain of the specimen appeared in its middle section. Therefore, the ratcheting strain at the middle of the specimen was selected for comparison.

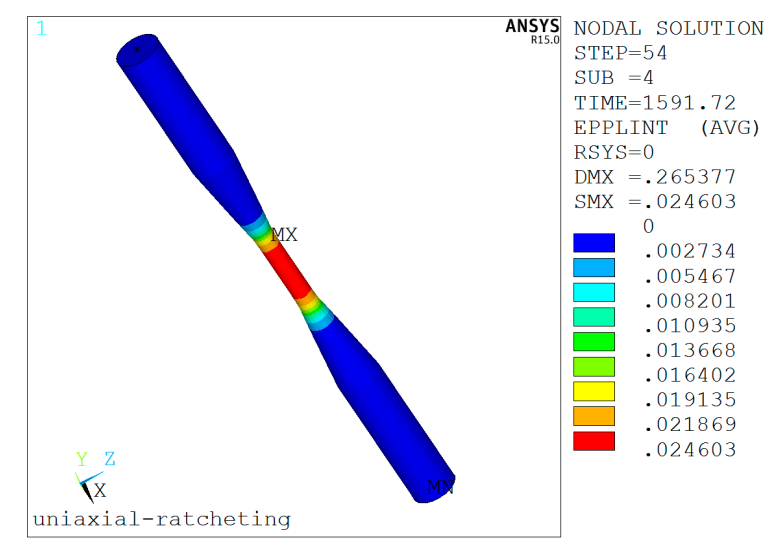

Figure 18. The total plastic strain of the finite element model.

Figure 19 shows the uniaxial ratcheting curve for the ratcheting strain of the specimen under different loading conditions by ANSYS. It can be seen from Figure 19 that the simulation of the uniaxial ratcheting strain with ANSYS was consistent with the experimental results and the MATLAB predictions.

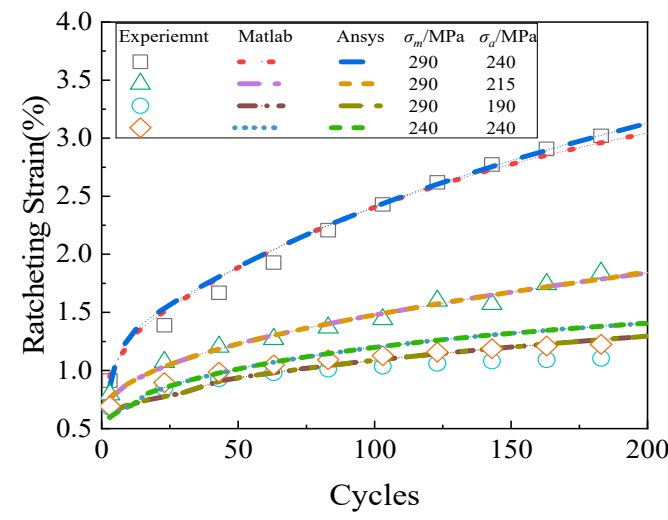

Figure 19. The simulation results of uniaxial ratcheting for the specimen. 


\section{Conclusions}

In this paper, we experimentally studied the uniaxial ratcheting behavior of S30408 austenitic stainless steel at $110 \mathrm{~K}$. Based on the Ohno-Wang II model, we proposed a new cyclic plasticity constitutive model with martensitic transformation. This was embedded into ANSYS with verification. The main results of the present work can be summarized as follows:

1. The proposed constitutive model with martensitic transformation reasonably predicted the ratcheting strain of S30408 at cryogenic temperatures. In the model, the influences of deformation-induced martensite on both isotropic hardening and kinematic hardening are considered.

2. By comparing the simulated and the experimental values of the deformation-induced martensite content under different loading conditions, we found that the proposed model could reasonably predict the martensite content at cryogenic temperatures.

3. The determination method of the model parameter $\omega_{m}$ to control the rate of reaching the martensite saturation value requires further investigations, and may be influenced by the temperature, the loading rate, etc.

Author Contributions: Carried out the experiment: Y.C. and K.Z.; performed the numerical simulations: Y.C. and X.C. (Xiaohui Chen); methodology: Y.C. and K.Z.; conceptualization: B.G. and X.C. (Xu Chen); writing —original draft preparation: Y.C.; writing-review and editing: X.C. and C.Y.; project administration: B.G; and funding acquisition: B.G. All authors provided critical feedback and agreed to the published version of the manuscript.

Funding: This research was supported by the National Key Research and Development Program of China, FC08086002017YFC0805600, and the Natural Science Foundation of Hebei Province of China, No. E2017202078.

Conflicts of Interest: The authors declare no conflict of interest.

\section{Nomenclature}

$\varepsilon \quad$ total strain tensor

$\varepsilon^{e} \quad$ elastic strain tensor

$\varepsilon^{p} \quad$ inelastic strain tensor

$\varepsilon^{b s} \quad$ Bain strain tensor

$\xi \quad$ martensite content

$\sigma \quad$ stress tensor (MPa)

E Young's modulus for elasticity (GPa)

$v \quad$ Poisson's ratio

$\sigma_{0} \quad$ size of yield surface (MPa)

$\sigma_{0.2} \quad$ yield strength $(\mathrm{MPa})$

$\sigma_{b} \quad$ tensile strength(MPa)

$\delta \quad$ elongation (\%)

$f \quad$ yield surface function

$\mathrm{J}_{2} \quad$ second deviatoric stress tensor invariant

$R \quad$ isotropic hardening parameter

$\alpha \quad$ deviatoric backstress tensor

$\alpha_{i} \quad$ the ith component of deviatoric backstress $\alpha$

$\overline{\alpha_{i}} \quad$ the magnitude of $\alpha_{\mathrm{i}}$

$\gamma_{i}, r_{i} \quad$ material constants

$m_{i} \quad$ material constants

s deviatoric stress

$H \quad$ Heaviside step function, $\mathrm{x} \geq 0, \mathrm{H}(\mathrm{x})=1 ; \mathrm{x}<0, \mathrm{H}(\mathrm{x})=0$

\langle\rangle$\quad$ Macauley's bracket, $x \geq 0,<x>=x ; x<0,<x>=0$

$b \quad$ rate of change of $\mathrm{R}$

$Q \quad$ saturation value of $\mathrm{R}(\mathrm{MPa})$ 
$\xi_{0} \quad$ initial value of martensite evolution

$\xi_{\infty} \quad$ limit value of martensite evolution

$\omega_{m} \quad$ evolution rate of martensite

$\left[M_{1}\right]$ non-zero auxiliary diagonal matrix, $[\mathrm{M} 1]=\operatorname{diag}[1,1,1,2,2,2]$

$\left[M_{2}\right] \quad$ non-zero auxiliary diagonal matrix, [M2] = diag $[1,1,1,1 / 2,1 / 2,1 / 2]$

$\mathrm{D}^{e} \quad$ isotropic elastic stiffness tensor

$h_{s} \quad$ plastic modulus

$\mathbf{I}_{s} \quad$ second-rank unit tensor

n normal direction of yield surface

$\mathbf{H}_{n+1}^{(i)} \quad$ fourth-rank tensor

\section{References}

1. Shi, X.P. Gas and LNG pricing and trading hub in East Asia: An introduction. Nat. Gas Ind. 2016, 3, 352-356. [CrossRef]

2. Gao, B.J.; Wang, B.; Zhai, L.H.; Shang, C.W. Random vibration analysis of the strip-supported cryogenic storage tank in transporting. J. Hebei Univ. Technol. 2018, 47, 48-52.

3. Armstrong, P.J.; Frederick, C.-O. A mathematical representation of the multiaxial bauschinger effect. Mater. High. Temp. 1966, 24, 1-26.

4. Chaboche, J.L. Time-independent constitutive theories for cyclic plasticity. Int. J. Plast. 1986, 2, 149-188. [CrossRef]

5. Chaboche, J.L. On some modifications of kinematic hardening to improve the description of ratcheting effects. Int. J. Plast. 1991, 7, 661-678. [CrossRef]

6. Ohno, N.; Wang, J.D. Kinematic hardening rules with critical state of dynamic recovery, Part I: Formulation and basic features for ratchetting behavior. Int. J. Plast. 1993, 9, 375-390. [CrossRef]

7. Ohno, N.; Wang, J.D. Kinematic hardening rules with critical state of dynamic recovery, Part II: Application to experiments of ratchetting bahavior. Int. J. Plast. 1993, 9, 391-403. [CrossRef]

8. Abdel-Karim, M.; Ohno, N. Kinematic hardening model suitable for ratcheting with steady-state. Int. J. Plast. 2000, 16, 225-240. [CrossRef]

9. Chen, X.; Jiao, R. Modified kinematic hardening rule for multiaxial ratcheting prediction. Int. J. Plast. 2004, 20,871-898. [CrossRef]

10. Zhang, J. Constitutive Description for Non-Proportionally Ratcheting of Cyclically Hardening Material and Its Finite Element Implementation at High Temperatures. Ph.D. Thesis, Southwest Jiaotong University, Chengdu, China, 2002.

11. Chen, G.; Zhao, X. Constitutive modelling on the whole-life uniaxial ratcheting behavior of sintered nano-scale silver paste at room and high temperatures. Microelectron. Reliab. 2018, 80, 47-54. [CrossRef]

12. Liu, X.Y.; Dong, Y.W.; Xiao, X. Study on constitutive model of cyclic ratcheting considering memory recovery of plastic strain. Chin. J. Sol. Mech. 2018, 39, 429-437.

13. Varvani-Farahani, A. A comparative study in descriptions of coupled kinematic hardening rules and ratcheting assessment over asymmetric stress cycles. Fatigue Fract. Eng. Mater. 2017, 40, 882-893. [CrossRef]

14. Rahman, S.M. Finite Element Analysis and Related Numerical Schemes for Ratcheting Simulation. Ph.D. Thesis, North Carolina State University, Raleigh, NC, USA, 2006.

15. Rahman, S.M.; Hassan, T.; Corona, E. Evaluation of cyclic plasticity models in ratcheting simulation of straight pipes under cyclic bending and steady internal pressure. Int. J. Plast. 2008, 24, 1756-1791. [CrossRef]

16. Hassan, T.; Kyriakides, S. Ratcheting of cyclically hardening and softening materials. Int. J. Plast. 1994, 10, 149-212. [CrossRef]

17. Kang, G.; Ohno, N.; Nebu, A. Constitutive modeling of strain range dependent cyclic hardening. Int. J. Plast. 2003, 19, 1801-1819. [CrossRef]

18. Kalnins, A.; Rudolph, J.; Willuweit, A. Using the nonlinear kinematic hardening material model of Chaboche for elastic-plastic ratcheting analysis. J. Press. Vessel Technol. 2015, 137, 031006. [CrossRef]

19. Halama, R. A modification of abdelkarim-ohno model for ratcheting simulations. Tech. Gaz. 2008, 15, 3-9.

20. Chen, X.H. A Study on the Ratcheting and Shakedown Behavior of Pressurized Piping Components under Cyclic Loading. Ph.D. Thesis, Tianjin University, Tianjin, China, 2013. 
21. Wang, Q.; Liu, X. Non-saturated cyclic softening and uniaxial ratcheting of a high-strength steel: Experiments and viscoplastic constitutive modeling. Mech. Mater. 2017, 113, 112-125. [CrossRef]

22. Olson, G.B.; Cohen, M. Kinetics of strain-induced martensitic nucleation. Met. Trans. 1975, 6A, 791-795. [CrossRef]

23. Stringfellow, R.G.; Parks, D.M.; Olson, G.B. A constitutive model for transformation plasticity accompanying strain-induced martensitic transformations in metastable austenitic steels. Acta. Metall. Mater. 1992, 40, 1703-1716. [CrossRef]

24. Tomita, Y.; Iwamoto, T. Constitutive modeling of trip steel and its application to the improvement of mechanical properties. Int. J. Mech. Sci. 1995, 37, 1295-1305. [CrossRef]

25. Sitko, M.; Skoczeń, B. Effect of $\gamma-\alpha^{\prime}$ phase transformation on plastic adaptation to cyclic loads at cryogenic temperatures. Int. J. Solids Struct. 2012, 49, 613-634. [CrossRef]

26. Xiong, Y.; Yue, Y.; He, T.T.; Fan, M.X.; Ren, F.Z.; Cao, W. Effect of rolling temperature on microstructure evolution and mechanical properties of AISI316LN austenitic stainless steel. MDPI Mater. 2018, 11, 1557. [CrossRef] [PubMed]

27. Naghizadeh, M.; Mirzadeh, H. Modeling the kinetics of deformation-induced martensitic transformation in AISI 316 metastable austenitic stainless steel. Vacuum 2018, 157, 243-248. [CrossRef]

28. Ji, S.Y. A Study on Cyclic Plasticity and Fatigue Mechanism of Strain Hardening S30408 Austenitic Stainless Steel. Master's Thesis, Tianjin University, Tianjin, China, 2019.

29. Garion, C.; Skoczen, B. Modeling of plastic strain-induced martensitic transformation for cryogenic applications. Int. J. Appl. Mech. 2002, 69, 755-762. [CrossRef]

30. Garion, C.; Skoczen, B.; Sgobba, S. Constitutive modelling and identification of parameters of the plastic strain-induced martensitic transformation in 316L stainless steel at cryogenic temperatures. Int. J. Plast. 2006, 22, 1234-1264. [CrossRef]

31. Gao, B.J. Modeling of Material Multiaxial Ratcheting and Ratcheting Prediction of Pressure Piping. Ph.D. Thesis, Tianjin University, Tianjin, China, 2005.

32. Hassan, T.; Zhu, Y.; Matzen, V.-C. Improved ratcheting analysis of piping components. Int. J. Press. Vessel. Pip. 1998, 75, 643-652. [CrossRef]

33. Kolasangiani, K.; Varvani-Farahani, A. Local ratcheting assessment of steel samples undergoing various step and block loading conditions. Theor. Appl. Fract. Mech. 2020, 107, 102533. [CrossRef]

34. Kang, G. A visco-plastic constitutive model for ratcheting of cyclically stable materials and its finite element implementation. Mech. Mater. 2004, 36, 299-312. [CrossRef]

35. Fischer, F.D. Transformation induced plasticity in triaxially loaded steel specimens subjected to a martensitic transformation. Eur. J. A Solids. 1992, 11, 233-244.

36. Cherkaoui, M.; Berveiller, M.; Sabar, H. Micromechanical modeling of martensitic transformation induced plasticity (TRIP) in austenitic single crystals. Int. J. Plast. 1998, 14, 597-626. [CrossRef]

37. Li, L.L. Study on Low Temperature Ratcheting Effect of Pre-Strain S30408. Master's Thesis, Hebei University of Technology, Tianjin, China, 2019.

38. Simo, J.C.; Taylor, R.L. Consistent tangent operators for rate-independent elastoplasticity. Comput. Method. Appl. Mech. Eng. 1985, 48, 101-118. [CrossRef]

39. Kobayashi, M.; Ohno, N. Implementation of cyclic plasticity models based on a general form of kinematic hardening. Int. J. Numer. Meth. Eng. 2002, 53, 2217-2238. [CrossRef]

40. Chen, X.H.; Chen, X.; Yu, D.J.; Gao, B.J. Recent progresses in experimental investigation and finite element analysis of ratcheting in pressurized piping. Int. J. Press. Vessel. Pip. 2013, 101, 113-142. [CrossRef]

(C) 2020 by the authors. Licensee MDPI, Basel, Switzerland. This article is an open access article distributed under the terms and conditions of the Creative Commons Attribution (CC BY) license (http://creativecommons.org/licenses/by/4.0/). 